\title{
Diálogo entre o Teórico e o Metodológico na Formação dos Professores de Geografia para o Ensino Secundário da Escola Paulista (1934-1960)
}

\author{
Dialogue between Theoretical and Methodological in College of Teachers of \\ Geography for the Secondary Education of the Paulista School (1934-1960)
}

\section{Diálogo entre lo Teórico y lo Metodológico en la Formación de los Profesores de Geografía para la Enseñanza Media de la Escuela Paulista (1934-1960)}

\author{
Márcia Cristina de Oliveira Mello ${ }^{1}$ \\ https://orcid.org/0000-0001-8517-3901
}

\begin{abstract}
RESUMO: Este artigo trata da formação dos primeiros professores de Geografia para atuar na escola secundária paulista. Destacamos o diálogo entre as orientações teóricas e metodológicas oferecidas pelo curso de formação docente em nível superior em Geografia (e História), ministrado pela Faculdade de Filosofia, Ciências e Letras da Universidade de São Paulo, entre os anos de 1934 e 1960. Com o objetivo de apontar as orientações que se configuraram enquanto matrizes teóricas de regulação do campo profissional docente em Geografia desenvolvemos pesquisa documental e bibliográfica que aponta características da orientação escolanovista, cujo pressuposto epistemológico era centrado sobre a concepção de criança que, por sua vez, direcionou as formas de se compreender o como se ensina e se aprende Geografia nas escolas. A problemática sobre a importância da relação entre teoria e prática pedagógica do curso contribuiu para compreender a gênese da história da formação docente em Geografia, auxiliando na reflexão sobre alguns problemas que até hoje enfrentamos quanto à maneira acadêmica e pedagógica de formar professores na área das humanidades. Do grupo de formandos da época surgiu uma geração de geógrafos e professores que fomentou o debate, a constituição do currículo e a didática da Geografia em nosso país.
\end{abstract}

PALAVRAS-CHAVE: Formação de professores de Geografia. Ensino de Geografia. Didática da Geografia.

ABSTRACT: This article deals with the formation of the first geography teachers to work in the Brazilian secondary school. We highlight the dialogue between the theoretical and methodological orientations offered by the first higher education teacher training course in Geography (and History), taught by the Faculty of Philosophy, Sciences and Letters of the University of São Paulo, between 1934 and 1960. In order to indicate the guidelines that were configured as theoretical matrices of regulation of the professional teaching field in Geography, we developed documentary and bibliographic research which points out characteristics of the New School orientation, whose

\footnotetext{
${ }^{1}$ Possui doutorado em Educação pela Universidade Estadual Paulista Júlio de Mesquita Filho. Professora da Universidade Estadual Paulista Júlio de Mesquita Filho. E-mail: marcia.mello@unesp.br.
} 
epistemological assumption was centered on the conception of a child, which in turn directed the ways of understanding how Geography is taught and learned in schools. The problematic about the importance of the relationship between theory and pedagogical practice of the course contributed to understand the genesis of the history of teacher education in Geography, helping to reflect on some problems that we still face today regarding the academic and pedagogical way of training teachers in the humanities. From the group of graduates of the time came a generation of geographers and teachers who fostered debate, curriculum constitution and didactics of geography in our country.

KEYWORDS: Geography teachers graduation course. Geography teaching. Didactics of Geography.

RESUMEN: Este artículo trata de la formación de los primeros profesores de Geografía para actuar en la escuela secundaria brasileña. Destacamos el diálogo entre las orientaciones teóricas y metodológicas ofrecidas por el primer curso de formación docente en nivel superior en Geografía (e Historia), ministrado por la Facultad de Filosofía, Ciencias y Letras de la Universidad de São Paulo, entre los años de 1934 y 1960. Dichas orientaciones se configuraron como matrices teóricas de regulación del campo profesional docente en Geografía. Se caracterizaron por la orientación escuelanovista, cuyo supuesto epistemológico se centraba en la concepción del niño como sujeto cognoscente, que a su vez direccionó las formas de comprenderse cómo se enseña y se aprende geografía en las escuelas. Entender el génesis de la historia de la formación docente en Geografía, en los años de 1930, auxilia en la reflexión sobre algunos problemas que hasta hoy enfrentamos cuanto a la forma académica y pedagógica de formar los profesores en el área de las humanidades. Del grupo de graduados de la época, surgió una generación de geógrafos y profesores que fomentó el debate, la constitución del currículo y la Didáctica de Geografía en nuestro país.

PALABRAS CLAVE: Formación de profesores de Geografía. Enseñanza de Geografía. Didáctica de Geografía.

\section{INTRODUÇÃO}

A formação acadêmica e pedagógica do professor de Geografia foi a preocupação em foco, nos últimos anos, quando desenvolvemos a pesquisa Orientações metodológicas destinadas aos professores de Geografia para o ensino secundário da escola paulista (1934-1960) (MELLO, 2019), junto ao curso de Geografia - Campus de Ourinhos, articuladamente à linha de pesquisa Ensino de Geografia, do Núcleo de Pesquisa em ensino de Geografia: articulação entre a universidade e a escola de Educação Básica. Contou com apoio financeiro da Fundação de Amparo à Pesquisa do Estado de São Paulo (FAPESP).

Neste artigo, apresentamos um recorte dos resultados obtidos na pesquisa com 0 objetivo de destacar as orientações que se configuraram enquanto matrizes teóricas de regulação do campo profissional docente em Geografia. Para isto, enfatizam-se as disciplinas pedagógicas e suas bases estruturantes, a saber: Psicologia Educacional, Metodologia do ensino secundário e Didática, oferecidas pelo primeiro curso em nível superior de formação docente em Geografia (e História), ministrado pela Faculdade de Filosofia, Ciências e Letras (FFCL), da Universidade de São Paulo (USP). 
As disciplinas foram selecionadas porque a Psicologia Educacional abarcou o pensamento escolanovista fundamentado na Biologia, na Sociologia e na própria Psicologia: o tripé da Escola Nova, o que justificou a cientificidade dos debates sobre os problemas educacionais da época. Já a disciplina de Metodologia do ensino secundário - substituída posteriormente por Didática - reuniu as orientações metodológicas necessárias ao preparo didático do professor dentro dos parâmetros escolanovistas. Essas contribuíram para estreitar o diálogo entre o teórico e o metodológico no que se referem às orientações destinadas aos professorandos, com o objetivo de promover uma revolução no pensar e no fazer a prática pedagógica entendendo a criança e seu processo de aprendizagem.

Por meio de pesquisa documental e bibliográfica de caráter histórico, buscamos identificar as orientações metodológicas destinadas aos professores do tipo "novo", "moderno", "científico" e "contextualizado" - termos recorrentes nas fontes selecionadas e relacionadas ao ideário da Escola Nova.

Para tanto, utilizamos procedimentos de identificação, reunião, organização e análise de fontes documentais contidas na legislação de ensino, a saber: o Decreto de criação da USP; o Regulamento do Instituto de Educação da USP; o Decreto de criação da Seção de Educação da FFCL da USP; a Lei que dispõe sobre o desdobramento dos Cursos de Geografia e História e o Decreto de criação da seção Educação da FFCL da USP.

O detalhamento das características do curso quanto aos aspectos teóricos e metodológicos foram obtidos por meio da análise dos programas de ensino das disciplinas selecionadas, publicados nos Anuários da FFCL da USP e nos periódicos Geografia, Boletim Geográfico, Boletim Paulista de Geografia e Revista Brasileira de Geografia.

Para subsidiar a reflexão sobre a pertinência dada pelo curso sobre a relação entre teoria e prática pedagógica, apoiamo-nos nos textos de caráter metodológico e científico, escritos por Pierre Monbeig e Aroldo de Azevedo e também nos relatos de professores do curso, destacados por Elza Nadai (1994). Por fim, realizamos uma entrevista com Amélia Americano Franco de Castro (1920-2020), em sua residência, na cidade de São Paulo/SP. As informações sobre sua atuação profissional oportunizaram reflexões aqui apresentadas (CASTRO, 2017).

A professora Amélia foi selecionada por ser a primeira professora de Didática Especial de Geografia do curso da USP com significativa representatividade no campo do ensino de Geografia em nosso país, além de estar disponível à época da coleta de dados para a pesquisa, assim como ter disponibilidade para participação. Informamos que na grafia dos sobrenomes da professora Amélia consta Franco de Castro nos arquivos dos matriculados e formandos da FFCL da USP. Após o casamento com Luiz Domingues de Castro observamse alterações em seus sobrenomes. 
Assim, julgamos importante investigar a relação entre o "otimismo pedagógico" e a nascente formação em nível superior, como um professor de Geografia se formava, já que alguns dos problemas enfrentados na atualidade estavam presentes na gênese do curso da USP.

\section{CARACTERÍSTICAS DO PRIMEIRO CURSO DE FORMAÇÃO DOCENTE EM GEOGRAFIA, NÍVEL SUPERIOR, NO BRASIL}

A formação de professores secundários para atuar nas escolas paulistas ganhou caráter propriamente universitário com a criação da USP, em 1934. O Instituto de Educação integrado à USP - desde sua origem, exclusivamente pela sua "Escola de Professores" assumiu compromisso com a formação dos primeiros docentes da área de humanidades, incluindo os professores de Geografia (e História). Geografia e História se mantiveram juntas até a implantação da Lei Federal n. 2.549, de 08/09/1955 (BRASIL, 1955), que dispôs sobre o desdobramento dos cursos de Geografia e História das Faculdades de Filosofia e Ciências; no entanto, nesse texto, daremos ênfase ao modelo teórico-metodológico adotado para a formação docente em Geografia.

O ano de 1934 foi um marco na formação docente em Geografia em nosso país. Matricularam-se no primeiro curso de Geografia e História - ministrado pela FFCL/USP - 24 seletos alunos, dos quais oito foram diplomados em 1936. Os primeiros licenciados em Geografia e História pela FFCL da USP foram, a saber: Antonio de Paula Assis, Nelson Camargo, Rezende Sampaio Garcia, Astrogildo Rodrigues de Mello, José de Oliveira Orlandi; Euripedes Simão de Paula, Affonso Antonio Rocco e João Dias da Silveira (UNIVERSIDADE DE SÃO PAULO, 1935a, 1936).

O primeiro formato do curso correspondeu aos três anos dedicados a disciplinas compostas de conteúdo específico do bacharelado e cursadas nos anos de 1934, 1935 e 1936 (Quadro 1), mais um ano dedicado para a formação do licenciado (Quadro 2); esse oferecido - concomitantemente - no ano de 1936. Este modelo de formação docente ficou conhecido como "três mais um", como nos lembra Tanuri (2000) em "História da formação de professores".

A grade curricular inicial se manteve até o ano de 1939 quando a cadeira de Geografia foi desdobrada em Geografia Física e Geografia Humana, sendo acrescentada uma terceira cadeira - Geografia do Brasil - a partir de 1942. Desse modo, o curso adotou a seguinte organização curricular para a Geografia: $1^{\circ}$ ano - Geografia Física e Humana; $2^{\circ}$ e $3^{\circ}$ anos Geografia Física, Geografia Humana e Geografia do Brasil. Além disso, a partir de 1950: "Os programas das cadeiras que formam o Departamento contêm uma parte fixa (noções 
básicas) e uma parte móvel, que varia para cada ano letivo" (AZEVEDO; SILVEIRA, 1949, p. 78).

Quadro 1 - Grade curricular inicial do curso de Geografia e História da FFCL da USP

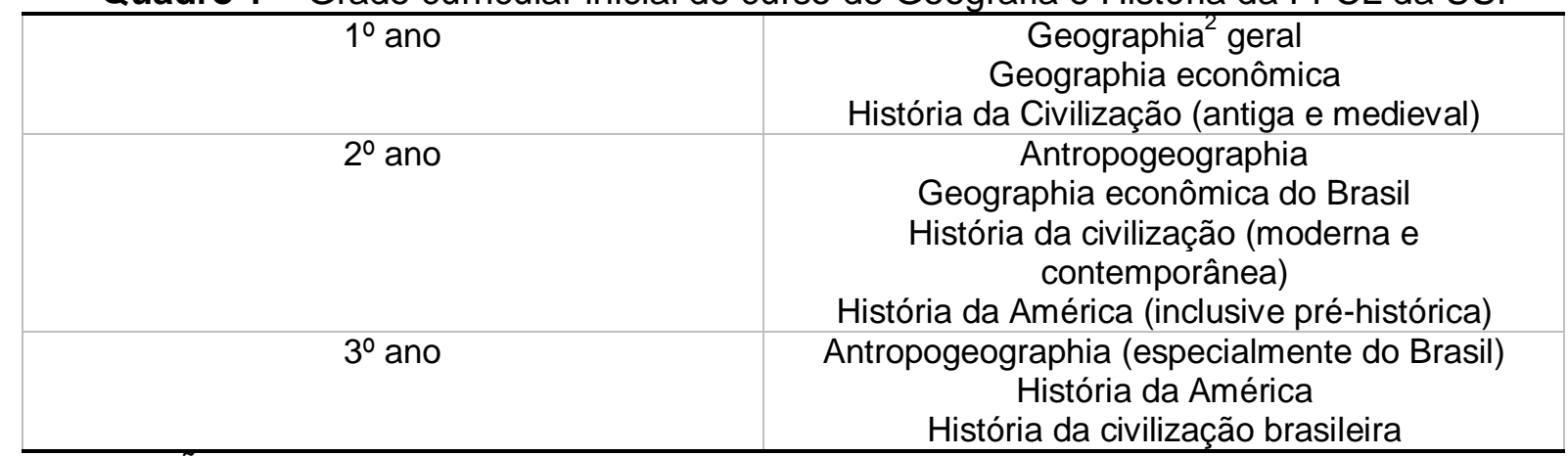

Fonte: SÁO PAULO, 1934.

Quadro 2 - Disciplinas do primeiro curso de formação pedagógica de professores secundários do Instituto de Educação, da USP

\begin{tabular}{|c|c|c|c|}
\hline \multicolumn{3}{|c|}{ Primeiro semestre } & \multirow{2}{*}{$\begin{array}{r}\text { Segundo semestre } \\
\text { História e Philosophia da Educação }\end{array}$} \\
\hline $\begin{array}{l}\text { Biologia } \\
\text { adolescent }\end{array}$ & Educacional applicada & ao & \\
\hline \multicolumn{3}{|c|}{ Psychologia Educacional } & Educação Secundaria Comparada \\
\hline \multicolumn{3}{|c|}{ Sociologia Educacional } & \multirow[t]{2}{*}{ Methodologia do Ensino Secundário } \\
\hline Methodolo & gia do ensino secundário & & \\
\hline
\end{tabular}

Fonte: SÄO PAULO, 1935.

Já as disciplinas pedagógicas que foram ministradas inicialmente no Instituto de Educação, no então denominado Curso de formação pedagógica de professores secundários do Instituto de Educação, da USP, são as que constam no quadro 2.

Esse formato curricular do então denominado Curso de formação pedagógica de professores secundários do Instituto de Educação se manteve nos anos de 1936, 1937 e no primeiro semestre de 1938. A partir do segundo semestre de 1938, com a mudança resultante do Decreto n. 9.268-A, de 25 de junho de 1938 (SÃO PAULO, 1938), que extinguiu o Instituto de Educação, a USP encorpou os cursos superiores oferecidos pelo Instituto.

Pelo artigo 20 do Decreto Lei n. 1.190/39 foi criado o Curso de Didática, substituindo o anterior. Desta forma, surgiu a cadeira de Didática Geral e Especial. A partir de 1940, aparecem os primeiros formados no Curso de Didática da USP que - adaptado à normatização federal, passou a ter a seguinte grade curricular: Didática Geral e Especial; Psicologia Educacional; Administração Escolar e Educação Comparada; Fundamentos Biológicos da Educação; e Fundamentos Sociológicos da Educação (UNIVERSIDADE DE SÃO PAULO, 1953a).

\footnotetext{
${ }^{2}$ Optamos por manter a ortografia de época nesta informação contida na legislação de ensino, assim como nas demais citações diretas das fontes documentais.
} 
$\mathrm{Na}$ evolução dos programas de ensino do curso de Didática da USP, encontramos - a partir de 1954 - a terminologia Didática Especial de Geografia, nomeando a disciplina que ficou sob a responsabilidade da professora Amélia Americano Domingues de Castro. A partir da Lei de Diretrizes e Bases n. 4.024, de 1961 (BRASIL, 1961), a Didática perdeu as caracterizações de Geral e Especial para ser substituída por Prática de Ensino sob a forma de Estágio Supervisionado.

No período de 1936 a 1960, formaram-se 384 professores de Geografia (e História). Dentre eles, nomes ilustres que se projetaram no cenário nacional como José de Oliveira Orlandi e João Dias de Silveira (da turma de 1936), Ary França (turma de 1938), Aroldo Edgard de Azevedo e Maria Conceição Vicente de Carvalho (da turma de 1939), Amélia Americano Franco de Castro (turma de 1940) e a Aziz Nacib Ab-Saber (turma de 1945) (MELLO, 2019).

A representatividade destes ex-alunos se deve ao fato de que eles ocuparam as primeiras cadeiras de docentes da USP, além de alguns terem experiência docente no então ensino secundário, fato esse que - possivelmente - tenha sido responsável por despertar, neles, o interesse pelo campo do ensino de Geografia.

A formação técnica projetada para ser oferecida em três anos era complementada com a formação pedagógica; naquela época, as faculdades de Filosofia e Ciências se constituíram enquanto lócus de formação de professores secundários.

As primeiras impressões apontam para o papel fundamental que o curso de formação de professores de Geografia e História da USP desempenhou para promover esta reflexão, especialmente por meio da organização interna da Didática da Geografia no estado de São Paulo e no Brasil. Esse papel se constituiu num conjunto de ideias, processos, formas e conteúdos fundamentados nos pressupostos psicológicos da aprendizagem (a inovação educacional que redescobriu a criança), validados cientificamente pela pedagogia científica, incluindo a Psicologia Educacional, conforme destaca Monarcha (1992).

Assim, eis o problema de pesquisa sobre o curso que analisamos: em que medida havia uma reflexão da importância da relação teoria e prática pedagógica na formação docente em Geografia? Os documentos que analisamos apontam tanto para as características que se aproximam do modelo que valoriza a cultura geral e o conhecimento específico quanto para o preparo didático-pedagógico do professor.

A pesquisa sobre o passado recente possibilita compreender como estas questões já foram pensadas e sistematizadas outrora; o presente passa a ser problematizado a partir de práticas que se constituíram em suas permanências e mudanças. Uma das questões ainda presentes na formulação de políticas para formação docente na atualidade envolve 
relativizar a relação teoria e prática pedagógica no ensino de Geografia, dicotomia do passado que aflige o presente e desafia o futuro do processo de formação docente.

\section{ESTABELECENDO UM DIÁLOGO ENTRE O TEÓRICO E O METODOLÓGICO NA FORMAÇÃO DOS PRIMEIROS PROFESSORES DE GEOGRAFIA DA FFCL DA USP}

Azevedo (1932) afirmava que uma das medidas a serem tomadas para uma necessária renovação educacional brasileira envolvia o processo de formação dos professores. Para ele, os docentes necessitavam de uma cultura múltipla, que Ihes possibilitassem acesso ao conhecimento dos homens e da sociedade, para perceberem o papel da escola e sua função, função esta que deveria servir aos interesses do indivíduo e não aos de classes sociais.

Saviani (2010) reforça que o Movimento da Escola Nova se valendo da "trindade cardinalícia" Fernando de Azevedo, Lourenço Filho e Anísio Teixeira tinha como objetivo principal a reconstrução educacional dos sistemas de ensino no Brasil. Lourenço Filho formulou as bases psicológicas do movimento escolanovista; Fernando de Azevedo foi responsável pelas bases sociológicas; e Anísio Teixeira articulou as bases filosóficas e políticas.

O professor Carlos Monarcha (1989), estudioso da Escola Nova brasileira, aponta que - no início do século XX - houve uma intensificação dos serviços públicos de ensino para atender às demandas sociais e políticas, dentro de um projeto capitalista de transição para a modernidade. Assim, o movimento escolanovista tentou mobilizar a sociedade sobre a necessidade da superação do atraso nacional; consequentemente ao ingresso no mundo moderno via escolarização. O progresso, por sua vez, materializado na cidade, impôs novas relações entre a vida social, o desenvolvimento e o controle do pensamento social.

Para tanto, era necessário conferir um caráter nacional à ampliação da escolarização, por meio da renovação dos métodos de ensino. A necessária renovação pedagógica tinha como princípios do novo e do moderno o ensino público, laico, gratuito, obrigatório como dever do Estado e oferecido em coeducação dos sexos.

A Pedagogia Nova se apresentava como científica porque na base da consciência educativa inovadora estavam as descobertas da Psicologia Educacional e os princípios formativos que se diferenciavam da Pedagogia Tradicional.

Nagle (1974) identificou a crença de colocar o Brasil no caminho do desenvolvimento, ao lado dos grandes países do mundo, por meio da difusão da escolarização à população, como a fase do "entusiasmo pela educação". A partir disto, desenvolveu-se o "otimismo pedagógico", cujos padrões apontavam que a escola poderia regenerar o homem brasileiro, consequentemente a própria sociedade. Tal otimismo, para Nagle, consolidou-se com o 
movimento da Escola Nova, utilizando a técnica como um de seus instrumentos; desta forma, as disciplinas pedagógicas de formação docente se alinharam a este processo.

Além da característica marcante da diversidade da psique infantil trazida pela Psicologia Educacional estava o ideal de democratização da escola, que se apresentava enquanto um projeto histórico, único e racional pelo seu compromisso com a construção de um presente racional e do futuro progressivo. O Estado seria dotado de uma universalidade que integraria o todo social na promoção da homogeneização da cultura, de acordo com a racionalidade do mundo produtivo, capaz de impor o domínio burguês no processo de modernização capitalista (MONARCHA, 1989).

A ciência, o industrialismo e a democracia balizaram a ideia do processo de transição social em direção à modernidade capitalista marcado - na expressão de Carlos Monarcha pela "ditadura da maioria", dos políticos e dos técnicos educacionais, já que a reorganização da escola e da sociedade foi atrelada aos interesses da classe dominante e serviu de porta de entrada para o autoritarismo e a disciplinação das massas, tarefas compatíveis com a formação do cidadão ao estilo europeu. Assim, os objetivos do ensino:

Deveriam ser aceitos como fins em si mesmos; questioná-los significava estar sob o domínio do pensamento ideológico. Sabemos que no discurso da ciência positiva não cabe à teoria buscar fins transcendentais, mas descobrir os meios para a realização dos fins que se presumem autoexplicativos (MONARCHA, 1989, p. 81).

Na medida em que a ciência fornecia as bases científicas para a nova educação, a nova sociedade brasileira comprometia também os projetos alternativos que poderiam contribuir para a reflexão sobre o papel da escola e do professor no país.Por sua vez, a Geografia escolar contribuiria significativamente:

[...] para o avanço científico do país fazendo a nação ultrapassar a cultura arcaica, conservadora e aristocrática hegemonizada e, enfim, adentrar para nunca mais sair da modernização em curso feita pelos chamados países desenvolvidos; tarefa hercúlea, porém pensada a partir de uma revolução social [...] (BATISTA, 2018, p. 8).

Desta forma, o autor provoca uma reflexão sobre o papel da disciplina frente aos propósitos da época. 


\section{A DISCIPLINA DE PSICOLOGIA EDUCACIONAL: MATRIZES TEÓRICAS DE FORMAÇÃO DOCENTE EM GEOGRAFIA}

A disciplina Psicologia Educacional foi criada no Instituto de Educação na reforma de Fernando de Azevedo; em 1936, ela era oferecida com duração semestral no curso de formação pedagógica de professores secundários que - posteriormente - transformou-se no Curso de Didática, como informado anteriormente.

No período analisado, a disciplina não sofreu mudanças estruturais conforme constam os dados obtidos no Anuário Universidade, da Cadeira de Psicologia Educacional, e nos Programas Aprovados pela Congregação (UNIVERSIDADE DE SÃO PAULO, 1936, 1953b, 1960).

Manuel Bergström Lourenço Filho (1897-1970) foi o professor da cátedra até ser substituído por Noemy da Silveira Rudolfer (1902-1980) (UNIVERSIDADE DE SÃO PAULO, 1953b); estes educadores formavam uma vanguarda escolanovista. O professor Lourenço Filho se envolveu diretamente nas questões relacionadas à Psicologia Educacional e suas aplicações educativas, seja como docente da disciplina, autor de textos sobre o tema, seja como gestor de instituições de ensino. "Foi por este caminho que ele atuou nos dois aspectos característicos da Escola Nova: a instrução técnico-profissional e a psicologia da infância" (SAVIANI, 2010, p. 204).

A Psicologia Educacional deu as bases científicas das novas concepções sobre sociedade, homem e criança/aluno; consequentemente, sobre os processos de ensino e aprendizagem. A nova concepção de aluno tinha em vista promover o desenvolvimento "natural" do educando, o que supostamente provocaria mudanças no aspecto interno da escola.

$\mathrm{Na}$ época os métodos tradicionais consideravam a programação do ensino visando a racionalização de procedimentos, eficiência e ênfase nos resultados, verificando se o comportamento dos alunos se alinhava com as metas previamente estabelecidas; também, as ideias comportamentalistas conviveram com o fantasma da repetência escolar. Por esses motivos, foram questionadas pelos reformadores do ensino.

A aprendizagem era entendida - então - como a repetição de um comportamento ou de uma classe de respostas. Dada a importância da programação, os debates sobre os métodos pedagógicos eram associados aos resultados do desempenho da aprendizagem dos alunos, ganhando centralidade nas preocupações pedagógicas.

No contexto da Escola Nova e a mudança de foco nos debates pedagógicos - dos métodos de ensino para as concepções da criança em processo de aquisição da aprendizagem - o novo conceito de aprendizagem se baseou nos interesses e nas necessidades da criança, em que o importante não é aprender coisas, mas aprender a 
observar, a pesquisar, a pensar, enfim, "aprender a aprender". Estas concepções perpassaram os programas da disciplina de Psicologia Educacional, conforme dados obtidos em Universidade de São Paulo (1936, 1938, 1953a, 1953b, 1960).

Lourenço Filho (1945) entendia prática de ensino enquanto "saber fazer". Destarte, o futuro professor aprenderia observando uma sala de aula, focando nas questões relativas às variáveis pedagógicas relacionadas aos aspectos material e humano, especialmente o estado biológico e psicológico dos alunos, a aprendizagem anterior, o interesse pela aprendizagem, os fatos acidentais ocorridos e os costumes da localidade. Assim, o objetivo do contato com a realidade da classe - por parte do professor - seria a compreensão biológica, psicológica e social da criança para, a partir disso, proceder com o "diagnóstico, prognóstico e hipóteses de correção". Desta forma, a prática seria bem planejada e metodicamente exercida favorecendo, ao futuro docente, o bom manejo de classe.

Esta forma de se pensar a prática de ensino tem impacto na atualidade sobre a organização utilizada na maioria das atividades de estágio supervisionado dos cursos de Licenciatura. O que, de início, era concebido enquanto "prática de ensino" atualmente corresponde ao que denominamos de "estágio supervisionado".

Batista (2018) explora o significado da incorporação dos preceitos da Escola Nova ao ensino de Geografia partindo de sua relação com o marco histórico do Manisfesto dos Pioneiros, de 1932. Analisando artigos publicados à época na seção "Contribuição ao Ensino", do Boletim Geográfico, aponta que o objetivo deste ensino, aliado à Pedagogia escolanovista, era formar cidadãos preparados para a nova fase do mundo capitalista. Assim,

[...] a escola que ensina Geografia moderna pode e deve forjar sujeitos felizes, competentes profissionalmente, socialmente comprometidos e ambientalmente éticos; formados permanentemente e dispostos a "aprender a aprender"; estudam o meio, propõem soluções para problemas contiguamente localizados e, é claro, desenvolvem o gosto pela intervenção (BATISTA, 2018, p. 8).

Para o autor, o lema escolanovista "aprender a aprender" ganhou espaço oportuno para sua expansão no ensino de Geografia. Justificados pela necessidade do avanço científico do país para a entrada na modernidade, os objetivos da disciplina deveriam prever a superação da cultura pedagógica arcaica e conservadora e adentrar na lógica do trabalho coletivo, do respeito mútuo e da solidariedade, enquanto elementos que impulsionariam a ordem e o progresso. O professor deveria considerar a atividade e não mais a atitude passiva do aluno; ele não ensinaria Geografia, mas ofereceria ao aluno os melhores elementos para que esse aprendesse Geografia de forma atrativa. 
As metodologias, os métodos e processos de ensino ativos garantiriam a superação dos métodos tradicionais de exposição oral, repetição da lição e verificação da aprendizagem, por meio da aplicação de experimentos didáticos, estudo do meio e resolução de problemas, entre outros.

Saviani (2012) reúne e apresenta reflexões sobre as necessárias críticas às pedagogias do "aprender a aprender". Fundamentadas na Pedagogia histórico-crítica, as oposições do autor se revelam na compreensão do próprio papel da educação escolar enquanto um trabalho não material. No ato de sua produção, ela não se separa dos elementos necessários à formação de cada indivíduo em singular; os conhecimentos, os conceitos, as ideias, os hábitos, os símbolos etc. devem ser produzidos na relação pedagógica de forma intencional e dialética.

A Pedagogia Nova - assim chamada por Demerval Saviani, na década de 1980 - é uma teoria não crítica da educação, por considerar a neutralidade do saber objetivo produzido historicamente. No contexto do primeiro terço do século $\mathrm{XX}$, caberia à educação escolar se adaptar ao progressivo desenvolvimento da sociedade guiada pela ordem e pelo progresso da nação. O reflexo dessa mentalidade nas orientações didáticas do curso de formação docente em Geografia se voltaram para a direção "Do estudo do meio, do conhecido ao desconhecido, da escuta à fala, da passividade à atividade e da cultura livresca à intervenção [...]" (BATISTA, 2018, p. 8). Ainda as orientações trariam "[...] possibilidades de construção do conhecimento discente que abarcam habilidades da ordem da observação, localização, representação, comparação, pesquisa, documentação, avaliação e reflexão" (lbid., p. 10).

Neste processo de transposição da Pedagogia escolanovista para o ensino de Geografia, percebe-se que a lógica interna do curso previa o preparo pedagógico do professor. No entanto, para Batista (2018), há um hiato entre o "dizer" e o "fazer" do ensino de Geografia de orientação escolanovista que - muitas vezes - não passou de simples modismo, mas que, oficialmente, balizou as prescrições curriculares deste campo de conhecimento por muitos anos, cujos resquícios ainda percebemos nas prescrições atuais.

\section{A DISCIPLINA DE METODOLOGIA DO ENSINO SECUNDÁRIO: MATRIZES TEÓRICAS DE FORMAÇÃO DOCENTE EM GEOGRAFIA}

De 1936 a 1938, a disciplina de Metodologia do Ensino Secundário foi ministrada com duração de dois semestres no então Curso de formação pedagógica de professores secundários do Instituto de Educação, da USP. Durante este período, seu programa de ensino (UNIVERSIDADE DE SÃO PAULO, 1935b) constava de cinco temas, descritos a seguir. 
I- Natureza e significado do ensino secundário.

II- O princípio do ensino secundário: a cultura geral e o despertar do espírito crítico, preparação para a vida.

III- O professor e o ensino secundário: preparação, função, a disciplina intelectual e moral a que ele deve se impor.

IV- O contato moral e mental com os alunos.

V- O professor secundário no meio social.

Para ministrar as aulas, "[...] foram contratados Paul Arbousse Bastide e Dora de Barros Pastorino, o primeiro como regente e a segunda como auxiliar de ensino" (NADAI, 1994, p. 160). Eles podiam "[...] contar com o apoio de outros docentes - tantos fossem as Secções apresentadas - para tratar das Metodologias Especiais. Nas primeiras décadas, elas foram tratadas sob forma de conferências [...]" (Ibid., p. 164), que, "[...] se destinavam a 'complementar, por especialistas de cada uma das matérias das escolas secundárias, 0 curso de formação techinica e profissional do professor de ensino secundário'" (UNIVERSIDADE DE SÃO PAULO, 1936, p. 224).

Para a abordagem sobre a metodologia do ensino de Geografia, foi escolhido o geógrafo francês Pierre Monbeig que se tornou - então - o primeiro docente da USP a sistematizar orientações metodológicas aos futuros professores de Geografia. Posteriormente Monbeig se envolveu no debate sobre o ensino de Geografia, integrando uma comissão da Associação dos Geógrafos do Brasil (AGB) para sugerir um programa para o ensino da Geografia no ensino secundário. O programa e as orientações metodológicas foram publicados nos artigos "O ensino secundário da Geografia”, em 1935, em coautoria com Aroldo de Azevedo e Maria Conceição Vicente de Carvalho e "A Geografia na escola secundária”, em 1945 (MELLO, 2019).

A familiaridade de Monbeig com a temática se deve possivelmente por sua sólida formação na Universidade de Paris em Letras (1927), Geografia Geral (1928) e História e Geografia (1929), aliada ao fato de que, em seu país, atuou como professor do ensino secundário no Liceu de Caen (UNIVERSIDADE DE SÃO PAULO, 1935a). Resumidamente, Monbeig, Azevedo e Carvalho (1935,) indicava:

- não fazer uso excessivo da memória;

- buscar uma Geografia "racional e inteligente";

- entender a Geografia enquanto uma disciplina de cultura geral; enquanto estudo da realidade imediata; e estudo da relação entre o homem e a natureza;

- utilizar recursos e processos didáticos como mapas, fotografias, leituras, observações e excursões geográficas; 
- partir do local na compreensão dos fenômenos geográficos para compará-los com regiões mais distantes.

As orientações de Monbeig contribuíram para a formação de um "novo profissional" atrelada ao panorama da era do capitalismo, da urbanização e industrialização que exigia novos rumos à educação. Assim, se por um lado o curso da USP "[...] originou-se marcado pela dualidade em sua formação: conteúdo científico, formação cultural de um lado e pedagógico, metodológico e técnico, de outro" (NADAl, 1994, p. 157), por outro, algumas ações fortaleciam a formação pedagógica, cujo foco se dava no último ano do curso. Certamente as tentativas de integração entre a formação específica do geógrafo e a pedagógica dialogavam intimamente com as bases teóricas da disciplina de Psicologia Educacional.

$\mathrm{Na}$ lista dos formandos do curso de formação pedagógica, do ano de 1936, constam os nomes de dois alunos desta primeira turma que se tornaram professores da USP, João Dias da Silveira (1913-1973) e José de Oliveira Orlandi (1892-1980) (MELLO, 2019).

Silveira publicou - em 1936 - o artigo "A excursão no ensino de Geographia". Tornouse, no ano de 1938, professor assistente da cadeira de Geografia da FFCL da USP, atuando nos cursos de Climatologia, Geografia das Comunicações e Relevo do Solo.

José de Oliveira Orlandi, jornalista colaborador do jornal O Estado de São Paulo, foi secretário da AGB e publicou os artigos "A methodologia do ensino geographico" e "O filme cinematographico na geographia”, em 1936 (MELLO, 2019).

Estes professores revelam um perfil de formação que previa, portanto, uma dimensão prática de aplicação e outra investigativa, tendo em vista a escolha de espaços em que os "alunos-mestres" poderiam concretizar atividades teóricas e práticas articuladas à Pedagogia escolanovista.

\section{A DISCIPLINA DE DIDÁTICA GERAL E ESPECIAL: MATRIZES TEÓRICAS DE FORMAÇÃO DOCENTE}

Pensar na formação pedagógica do professor de Geografia e na epistemologia do ensino de Geografia requer um olhar sobre o processo histórico de construção e apropriação que se fizeram a respeito do que seja ensinar-aprender Geografia. Neste sentido, o estudo de alguns aspectos da disciplina Didática Especial em Geografia pode nos orientar na compreensão das matrizes teóricas implicadas no pensar o ensino da disciplina nas escolas, que despertam - até os dias de hoje - possibilidades variadas de processos de ensino que, se já não se configuram como modelos do "novo", permanecem nas orientações oficiais como práticas que podem ser bem-sucedidas. 
Dentre os métodos, processos e técnicas mais difundidos no curso estavam: centros de interesse, estudo dirigido, unidades didáticas, métodos de projetos, fichas didáticas, contrato de ensino, excursões, projetos de ensino e estudo do meio.

Conforme informações localizadas em A criação dos Cursos de Didática e Pedagogia (UNIVERSIDADE DE SÃO PAULO, 1953a), desde 1939 a cadeira de Didática Geral e Especial foi organizada contendo um plano de trabalho desenvolvido em duas partes; a primeira denominada teórica, a cargo de um professor catedrático responsável pela Didática Geral; a segunda, denominada de prática, a cargo dos professores auxiliares, abrangendo, então, as Didáticas Especiais.

Durante o curso de Didática, os alunos eram agrupados conforme as disciplinas afins. Para cada grupo um professor assistente orientava a Metodologia Especial e a prática de ensino dos alunos, que, por sua vez estava dividida em três fases - observação, coparticipação, e direção de classe. Tais atividades foram denominadas de estágios e deveriam ocorrer na escola secundária.O processo de prática de ensino era desenvolvido em três fases:

1- Fase de observação, em que o participante assiste [...] à aula na escola secundária, dada por professor de estabelecimento oficial ou particular. 2 Fase de co-participação, em que o praticante familiarizado com a situação do professor na direção de classe e com os próprios alunos, poderá auxiliar o professor no repetir a lição, no dar exercícios de fixação, no preparar matérias para a aula, no fazer a chamada, etc. 3- Fase da direção de classe, em que se aproveitam os momentos oportunos para substituir professores em licença, ou que devem faltar por vários dias. Depois de orientado, tentará a direção real de classes e a imitar os processos usados que deram bons resultados (UNIVERSIDADE DE SÃO PAULO, 1953a, p. 439).

De acordo com os Programas aprovados pela Congregação (UNIVERSIDADE DE SÃO PAULO, 1954, 1960), dentre os fundamentos do currículo para a formação docente, constavam na bibliografia das disciplinas textos de autores como John Dewey (1859-1952); Édouard Claparède (1873-1940); Anísio Teixeira (1900-1971); Antonio Firmino de Proença (1880-1946); Delgado de Carvalho (1884-1980); e Manuel Bergström Lourenço Filho (18971970). Estes autores, adeptos dos métodos ativos, reforçaram a necessidade da substituição do método expositivo pelos modernos.

Para Silva (2012), a influência da Geografia "moderna", sobretudo com o impulso de Delgado de Carvalho, estimulou um novo "quadro didático" à Geografia. Naquele momento, a Didática era entendida: 
[...] como um conjunto de ideias e métodos, privilegiando a dimensão técnica do processo de ensino, fundamentada nos pressupostos psicológicos e experimentais, cientificamente validados na experiência e constituídos em teoria [...]. A Didática, assim concebida propiciou a formação de um novo perfil de professor: o técnico (VEIGA, 1995, p. 32).

Dentre os técnicos, destacamos a atuação da ex-aluna do curso que analisamos Amélia Americano Domingues de Castro - que foi contratada, em 1942, como professora substituta da disciplina de Didática. Ela doutorou-se em 1950, orientada por Noemy da Silveira Rudolfer. Em sua atuação e produção intelectual, preocupou-se com os temas relativos aos processos didáticos: as bases psicológicas da aprendizagem, a exposição do assunto, a direção da aprendizagem, a seleção e o uso do material de ensino e a verificação do aprendizado.

No programa de ensino elaborado pela professora Amélia (UNIVERSIDADE DE SÃO PAULO, 1954) encontramos os seguintes temas: os estudos sobre a evolução do ensino de Geografia, a importância e objetivos da disciplina, suas bases psicológicas e lógicas e os processos didáticos (planos de aula, métodos e técnicas adequados ao ensino de Geografia, materiais de ensino, direção de classe e avaliação da aprendizagem).

Levando em consideração a necessidade de nosso país formar não apenas pesquisadores, mas também professores para a escola secundária, Aroldo de Azevedo informou no texto "Dez anos de ensino superior de Geografia" que ele não deixava esta função apenas para o Curso de Didática. Enquanto professor da disciplina de Geografia do Brasil contribuía para conduzir a formação pedagógica dos geógrafos, desde o primeiro ano do curso.

No $1^{\circ}$ ano, costumo iniciar meus alunos no terreno da bibliografia. Procurando demonstrar o inestimável valor das fontes de consulta, quer sejam livros, quer sejam revistas especializadas, tanto conduzi-los à organização de seu primeiro fichário geográfico. É claro que me limito a lançar a semente, esperando que o aluno saiba cultivá-la e possa, com o tempo, dispor de um razoável fichário para os seus próprios estudos. No $2^{\circ}$ ano, durante o primeiro semestre, faço-os elaborar planos de aula, dentro de um programa da $1^{\text {a }}$ série ginasial. Trata-se de uma experiência inicial, a fim de conduzir o aluno ao bom caminho do método e da ordenação lógica dos assuntos a abordar. Elaborado o plano, é o mesmo discutido em classe, de maneira que todos possam colaborar e dar sua opinião. No segundo semestre, os alunos devem fazer resenhas bibliográficas, isto é, resumem para seus colegas um artigo de revista, alguns capítulos de um livro ou dão uma idéia geral de uma obra que haja lido. Constituem o que costumo chamar de "aula baseada num só autor", realmente, afinal de contas, o aluno faz, com tais resenhas, uma primeira experiência de como dar uma aula, com a facilidade de não ter de se preocupar com bibliografia. Iniciou, assim, na prática da exposição oral, o que Ihes dará desembaraço e mais fácil manejo da palavra, para o futuro. No $3^{\circ}$ ano do curso de Bacharelado, enfim, os alunos devem dar aulas de verdade, embora destinadas a seus colegas (AZEVEDO, 1946, p. 234-235, grifo nosso). 
Azevedo utiliza a nomenclatura "Didática da Geografia" ao relatar sua experiência de articular pesquisa e ensino, e teoria e prática pedagógica. Assim, nas palavras de Azevedo "[...] os alunos chegam ao curso de Didática com uma certa dose de experiência, que sempre Ihes há de ser útil; e estão mais ou menos preparados para a vida prática" (Ibidem, p. 235).

A preocupação de Azevedo (1946), na formação do futuro docente para a atuação no campo profissional articuladamente com a formação universitária, possivelmente gerou um forte debate na época, já que o Decreto n. 9.053, de 12 de março de 1946, estabeleceu a obrigatoriedade das Faculdades de Filosofia e Ciências manterem uma escola de aplicação, com o objetivo de favorecer a articulação entre a teoria e a prática pedagógica.

No percurso histórico de constituição da Didática da Geografia, observamos um forte indício da tentativa de oferecer aos professores orientações metodológicas capazes de ampliar o debate sobre a dicotomia entre a teoria e prática. Um fator que contribuiu para isto foi a revolução copernicana sobre a concepção de criança, o sujeito cognoscente de Jean Piaget. Neste sentido, no campo do ensino de Geografia, cada aluno reconstruiria nas grandes linhas os conceitos e categorias geográficas de forma sucessiva, iniciando pelas relações topográficas e, a partir delas, seriam estabelecidas as relações projetivas e euclidianas, dentro de um processo evolutivo do nível de desenvolvimento mental (OLIVEIRA, 1977).

Esta teoria envolve a interação entre o sujeito cognoscente e o objeto de conhecimento e a (re) construção do conhecimento. Para Piaget, o sujeito cognoscente é o sujeito pensante ou epistêmico "[...] que há de comum a todos os sujeitos, posto que as coordenadas gerais das ações implicam um universal que é o da própria organização biológica" (BATTRO, 1978, p. 227-228).

Por meio desta interação, a criança se envolve em um processo de construção ativo de natureza cognitiva; esse processo de construção do conhecimento em relação à aprendizagem dos conceitos geográficos - por exemplo - envolve a criança; em interação com o objeto de conhecimento (espaço geográfico), ela constrói hipóteses sobre o objeto até chegar a interpretar suas propriedades. Isso faz com que, mesmo antes de compreender o espaço geográfico convencionalmente, a criança - sujeito cognoscente - trata de organizar critérios para interpretar as características formais do espaço; trata-se, portanto, de um processo de "reconstrução" do conhecimento e não de apropriação do conhecimento pronto.

Diante dos preceitos da teoria piagetiana, as discussões sobre as orientações didáticas se aproximaram das características psicológicas dos alunos, o que poderia mudar os paradigmas de ensino: do privilégio da memorização para a curiosidade do sujeito 
cognoscente; da cópia do texto do manual de ensino para a pesquisa como atividade inerente ao processo de ensino-aprendizagem; da certeza da eficiência do aparato metodológico para a pesquisa como possibilidade de ensino. Eis aqui o encontro entre o teórico e o metodológico.

A professora Amélia informou - por meio de entrevista - que ela contribuiu para a entrada das ideias de Piaget na USP, quando esse pensador era lido em francês, e ela mesma fazia as traduções livres para suas aulas de Didática. Como a produção intelectual da professora Amélia foi fortemente influenciada por Jean Piaget, podemos concluir que ela encontrou no psicólogo suíço o referencial teórico adequado para a época. Amélia explicou ainda que o problema inicial era pensar em como ensinar a ensinar pois não havia um modelo teórico pronto; a partir de Piaget, ela obteve a resposta (CASTRO, 2017).

A partir da teoria ampla e complexa formulada pelo pesquisador suíço sobre o processo de construção do conhecimento, em que as crianças aprendem por experiência cada vez mais complexas, que partem do concreto para o abstrato, as práticas pedagógicas deveriam ser planejadas e aplicadas. Assim, cada criança reproduziria nas grandes linhas a filogênese: o conhecimento produzido pela humanidade. Na nossa interpretação esta foi a maior contribuição da professora Amélia para a Didática da Geografia, que mais tarde influenciou a produção sobre a cartografia escolar, ou o estudo cognitivo do mapa, a citar os estudos da professora Lívia de Oliveira, baseados todos nas provas piagetianas.

Os avanços na tentativa de compreender a relação entre o teórico e metodológico balizou a Didática da Geografia no campo da formação docente. Já na prática pedagógica, Rocha (2000, p. 18) adverte:

\begin{abstract}
Evidentemente que a nova orientação adotada para o ensino de geografia, mesmo tendo adquirido o status de modelo oficial, não levou ao desaparecimento da concepção clássica de geografia escolar, marcada pela prática meramente descritiva, mnemônica, enciclopédica e distante da realidade dos sujeitos sociais envolvidos no processo de ensinoaprendizagem. De concreto, pode-se afirmar que com as propostas apresentadas por Delgado de Carvalho e seus seguidores a geografia escolar brasileira tornou-se efetivamente objeto de questionamentos, não só no que diz respeito aos seus métodos, mas também em relação aos conteúdos de ensino adotados por seus (suas) professores (as).
\end{abstract}

Estas reflexões são também expostas por Vlach (1988), quando enfatiza o papel da Geografia de reforçar a inculcação da ideologia do nacionalismo patriótico no percurso histórico de sua constituição como disciplina autônoma. Também Silva (2012, p. 355-356) adverte: "Assim, o ensino de Geografia, com intensidade variante, assumiu um duplo papel: o da nacionalização e o da cultura geral, além de formar cientificamente liberais e técnicos. Perpassou, portanto, um papel cultural, um papel nacional e um papel científico". 


\section{CONSIDERAÇÕES FINAIS}

As características do primeiro curso de formação docente em nível superior da USP, com destaque ao de Geografia (e História) permitem compreender determinadas "matrizes" de ordenação de um campo que em sua origem se preocupou com o preparo científico do professor e sua prática educativa.

Do grupo de formandos, dos anos de 1934 a 1960, surgiram brilhantes geógrafos e professores para atuar na escola brasileira. O curso da USP contribuiu para regular a ordem das práticas pedagógicas em Geografia em nosso país e - ao mesmo tempo - fomentou debates que favoreceram a organização do próprio currículo da escola secundária.

O modelo de formação docente, adotado à época pela USP, contribuiu para a constituição do campo profissional docente em Geografia. Essa matriz caracterizada pela orientação escolanovista teve inúmeras variáveis, cujas versões são passíveis de investigação para compreendermos o presente e as múltiplas angústias da formação inicial na área. Assim, entender como a formação docente foi pensada no passado recente de forma acadêmica e sistematizada, entre o "otimismo pedagógico" e o patriotismo nacionalista, pode auxiliar na compreensão de que não se mudam práticas e concepções a curto prazo.

Certamente, as "matrizes" de regulação do campo foram influenciadas pelo diálogo teórico e metodológico promovido pelas disciplinas pedagógicas que possibilitaram articular aspectos psicológicos da aprendizagem dos conceitos geográficos ao papel dos professores de Geografia que - apropriando-se das orientações metodológicas oferecidas pelo curso optaram por práticas que podem despertar, ainda nos dias de hoje, novas possibilidades no ensino de Geografia. Essas contemplam o estado psicológico, biológico e social dos alunos; incentivam a liberdade, a autonomia e criatividade dos alunos e - acima de tudo - ampliam visões de mundo para que todos possam superar o antidiálogo presente em alguns contextos de nossa sociedade.

Por fim, registramos nossa homenagem em forma de agradecimento à professora Amélia Americano Domingues de Castro, que morreu no ano de 2020, nos deixando um legado intelectual com múltiplas possibilidades para ensinar e aprender Geografia.

\section{REFERÊNCIAS}

AZEVEDO, Aroldo de. Dez anos de ensino superior de Geografia. Revista Brasileira de Geografia, São Paulo, v. 3, n. 2, p. 227-242, abr./jun. 1946. 
AZEVEDO, Aroldo de; SILVEIRA, João Dias. O ensino de Geografia na Faculdade de Filosofia da Universidade de São Paulo. Boletim Paulista de Geografia, São Paulo, n. 3, p. 76-83, out. 1949.

AZEVEDO, Fernando de. A reconstrução educacional no Brasil ao povo e ao governo: manifesto dos pioneiros da educação nova. São Paulo: Companhia Editora Nacional, 1932.

BATISTA, Bruno Nunes. O ensino de Geografia paga tributo à Escola Nova? Geosaberes, Fortaleza, v. 9, n. 19, p. 1-16, set./dez. 2018.

BRASIL. Lei n. 2.549, de 08 de setembro de 1955. Dispõe sobre o desdobramento dos Cursos de Geografia e História nas Faculdades de Filosofia. Diário Oficial da União: Seção 1, Brasília, DF, p. 17273, 14 set. 1955.

BRASIL. Lei n. 4.024, de 20 de dezembro de 1961. Fixa as Diretrizes e Bases da Educação Nacional. Diário Oficial da União, Brasília, DF, p. 11429, 27 dez. 1961.

BATTRO, Antonio M. Dicionário terminológico de Jean Piaget. São Paulo: Pioneira, 1978.

CASTRO, Amélia Americano Domingues de. [Entrevista cedida a], Márcia Cristina de Oliveira Mello. [S. I.], 2017. Manuscrito.

LOURENÇO FILHO, Manoel Bergström. Prática de ensino. Arquivos do Instituto de Educação, Rio de Janeiro, v. 2, n. 4, p. 33-42, dez. 1945.

MELLO, Márcia Cristina de Oliveira. Relatório científico "Orientações metodológicas destinadas aos professores de Geografia para o ensino secundário da escola paulista (1934-1960)". Ourinhos: UNESP, 2019. FAPESP Processo n. 2014/01139-5, vigência de 01/03/2017 a 31/08/2019.

MONARCHA, Carlos. A reinvenção da cidade e da multidão: dimensões da modernidade brasileira - a Escola Nova. São Paulo: Autores Associados, 1989.

MONARCHA, Carlos. As três fontes da Pedagogia científica: a Psicologia, a Sociologia e a Biologia. Didática, Marília, v. 28, p. 41-49, 1992.

MONBEIG, Pierre; AZEVEDO, Aroldo de; CARVALHO, Maria Conceição Vicente de. O ensino secundário da Geografia. Geografia, São Paulo, v. 1, n. 4, p. 107-113, 1935.

MONBEIG, Pierre. A Geografia no Ensino secundário. Boletim Geográfico, São Paulo, v. 3, n. 26, p. 163-171, maio 1945.

NADAI, Elza. Fernando de Azevedo e a formação pedagógica do professor secundário: o Instituto de Educação. Revista da Faculdade de Educação, São Paulo, v. 20, n. 1/2, p. 151-172, jan./dez. 1994.

NAGLE, Jorge. Educação e sociedade na Primeira República. São Paulo: EDUSP, 1974.

OLIVEIRA, Livia de. Estudo metodológico e cognitivo do mapa. 1977. Tese (Livre Docência) - Universidade Estadual Paulista, Rio Claro, 1977.

ROCHA, Genylton Odilon Rêgo da. Delgado de Carvalho e a orientação moderna no ensino da Geografia escolar brasileira. Terra Brasilis, Niterói, n. 1, p. 1-19, jan. 2000.

SÃO PAULO (Estado). Decreto n. 6.283, de janeiro de 1934. Cria a Universidade de São Paulo e dá outras providências. Diário Oficial do Estado, São Paulo, 25 jan. 1934.

SÃO PAULO (Estado). Decreto n. 7.067, de 06 de abril, de 1935. Aprova o regulamento do Instituto de Educação, da Universidade de São Paulo. São Paulo: Secretaria da Educação e da Saúde Publica, $1935 . \quad$ Disponível em: https://www.al.sp.gov.br/repositorio/legislacao/decreto/1935/decreto-7067-06.04.1935.html. Acesso em: 10 out. 2020.

SÃO PAULO (Estado). Secretaria Geral Parlamentar. Decreto n. 9.268-A, de 25 de junho de 1938. Extingue o Instituto de Educação, cria a secção de Educação da Faculdade de 
Filosofia, Ciências e Letras da Universidade de São Paulo e dá outras providências. São Paulo: Secretaria Geral Parlamentar, 1938.

SAVIANI, Dermeval. História das ideias pedagógicas no Brasil. Campinas: Autores Associados, 2010.

SAVIANI, Dermeval. Pedagogia histórico-crítica: primeiras aproximações. Campinas: Autores Associados, 2012.

SILVA, Jeane Medeiros. A bibliografia didática de Geografia: história e pensamento do ensino geográfico no Brasil (1814-1930). 2012. Tese (Doutorado em Geografia) Universidade Federal de Uberlândia, Uberlândia, 2012.

TANURI, Leonor Maria. História da formação de professores. Revista Brasileira de Educação, Rio de Janeiro, n. 14, p. 61-88, maio/ago. 2000.

UNIVERSIDADE DE SÃO PAULO. Faculdade de Filosofia, Ciências e Letras. Anuário universidade 1934-1935. São Paulo: USP, 1935a.

UNIVERSIDADE DE SÃO PAULO. Archivos do Instituto de Educação. São Paulo: USP, 1935b.

UNIVERSIDADE DE SÃO PAULO. Anuário universidade 1936. São Paulo: USP, 1936.

UNIVERSIDADE DE SÃO PAULO. Anuário universidade 1937-1938. São Paulo: USP, 1938.

UNIVERSIDADE DE SÃO PAULO. Anuário da Faculdade de Filosofia, Ciências e Letras 1939-1949. A criação dos Cursos de Didática e Pedagogia. São Paulo: USP, 1953a.

UNIVERSIDADE DE SÃO PAULO. Cadeira de psicologia educacional. São Paulo: USP, 1953b.

UNIVERSIDADE DE SÃO PAULO. Faculdade de Filosofia, Ciências e Letras. Programas aprovados pela congregação para o ano letivo de 1954. São Paulo: USP, 1954.

UNIVERSIDADE DE SÃO PAULO. Faculdade de Filosofia, Ciências e Letras. Programas aprovados pela congregação para o ano letivo de 1960. São Paulo: USP, 1960.

VEIGA, IIma Passos Alencastro. Didática: uma retrospectiva histórica. In: VEIGA, IIma Passos Alencastro (coord.). Repensando a Didática. Campinas: Papirus, 1995. p. 25-40.

VLACH, Vânia Rúbia Farias. A propósito do ensino de Geografia: em questão, o nacionalismo patriótico. 1988. Dissertação (Mestrado em Geografia) - Universidade de São Paulo, São Paulo, 1988. 